\title{
Whole Genome Amplification
}

National Cancer Institute

\section{Source}

National Cancer Institute. Whole Genome Amplification. NCI Thesaurus. Code C19590.

Any technique designed to amplify a limited genomic DNA sample so as to generate a

new sample that is indistinguishable from the original but with a higher DNA

concentration. 